\title{
Mechanistic Modeling of the Pharmacodynamic and Pharmacokinetic Relationship of Tissue Factor Pathway Inhibitor-Neutralizing Antibody (BAY 1093884) in Cynomolgus Monkeys
}

\author{
Jian-Ming Gu, ${ }^{1,4}$ Xiao-Yan Zhao, ${ }^{1}$ Thomas Schwarz, ${ }^{2}$ Joachim Schuhmacher, ${ }^{2}$ Andreas Baumann, ${ }^{3}$ Elena Ho, ${ }^{1}$ \\ Babu Subramanyan, ${ }^{1}$ Kathy Tran, ${ }^{1}$ Timothy Myles, ${ }^{1}$ Chandra Patel, ${ }^{1}$ and Maria Koellnberger ${ }^{2}$
}

\begin{abstract}
Received 15 December 2016; accepted 12 April 2017; published online 17 May 2017
Abstract. $\quad$ BAY 1093884 is a fully human monoclonal antibody against the tissue factor pathway inhibitor (TFPI) in development as prophylaxis in patients with hemophilia with or without inhibitors. In vitro, BAY 1093884 binds to human, mouse, and monkey TFPI. The objective of this study was to find a pharmacodynamic (PD) biomarker after administration of BAY 1093884 to normal monkeys. In monkey plasma, BAY 1093884 exhibited an IC $_{50}$ (concentration that inhibits $50 \%$ ) of 4.65 and $6.19 \mathrm{nM}$ for free TFPI and diluted prothrombin time (dPT), respectively. The BAY 1093884 pharmacokinetic (PK) profile and its PD effects on $\mathrm{dPT}$ and free TFPI levels were assessed after intravenous and subcutaneous administration of BAY 1093884 (5 and $20 \mathrm{mg} / \mathrm{kg}$ ) to female cynomolgus monkeys. Free TFPI concentrations in plasma decreased rapidly and increased to baseline in a dose-dependent manner. dPT clotting time was shortened and correlated with free TFPI levels and drug concentration in plasma, demonstrating the relationship between PD activities (dPT clotting time and free TFPI levels) and drug concentration. BAY 1093884 exhibited nonlinear PK, and a target-mediated drug disposition model was used to characterize the BAY 1093884 versus TFPI concentration-response relationship. We concluded that a mechanism-based PK/ PD binding model could be useful for predicting human response to BAY 1093884. For the first-in-human study, measurement of free TFPI will be included as part of the doseescalation design.
\end{abstract}

KEYWORDS: monoclonal antibody; pharmacodynamics; pharmacokinetics; tissue factor pathway inhibitor.

JEL CLASSIFICATION: pharmacokinetics; pharmacodynamics; pharmacogenomics.

\section{INTRODUCTION}

BAY 1093884, a fully human monoclonal antibody (mAb; immunoglobulin G2 [IgG2]) against tissue factor pathway inhibitor (TFPI) developed as prophylaxis for persons with hemophilia with or without inhibitors, is currently in a phase 1 clinical trial. In vitro, BAY 1093884 binds to human, mouse, rat, rabbit, dog, and monkey TFPI. TFPI is one of three major anticoagulants in blood circulation and presents primarily in alpha granules of platelets and the

Jian-Ming Gu, Elena Ho, Kathy Tran, and Timothy Myles were employed at Bayer at the time this study was conducted.

${ }^{1}$ US Innovation Center, Bayer, 455 Mission Bay Blvd, South San Francisco, California 94158, USA.

${ }^{2}$ Bayer AG, Wuppertal, Germany.

${ }^{3}$ Bayer AG, Berlin, Germany.

${ }^{4}$ To whom correspondence should be addressed. (e-mail: gufangjiu@yahoo.com) surface of endothelium (1). The mean plasma TFPI concentration in healthy individuals is $\sim 1.6 \mathrm{nM}$, and about $80 \%$ of the circulating TFPI is bound to lipoprotein (2).

Tissue factor pathway inhibitor plays an essential role primarily in the extrinsic pathway of the coagulation cascade and acts as an anticoagulant. TFPI is a member of the multivalent Kunitz-type serine protease inhibitors. It is now known that TFPI dampens the blood coagulation pathway by blocking the activity of two of the major protease-cofactor complexes, TF/activated factor VII (FVIIa)/activated factor X (FXa) (3) and prothrombinase (4). This ability of TFPI to alter the contribution of the TF/FVIIa/Tenase and Prothrombinase complexes to thrombin generation can be exploited to treat bleeding disorders, and pharmacologic inhibitors of TFPI activity can restore hemostasis in animal models of hemophilia (5).

Hemophilia A and B are genetic disorders caused by deficiency of FVIII or FIX, respectively. In principle, blocking TFPI activity can restore FXa and TF/FVIIa activity, thus 
prolonging the duration of action of the tissue factor pathway and amplifying generation of FXa, the lack of which is the common defect in hemophilia A and B. TFPI inhibitor (fucoidan) and aptamer ARC19499 have been shown to block FXa inhibition by TFPI and to be beneficial in restoring hemostasis and reducing blood loss in hemophilia A mice and induced hemophilia monkey models $(6,7)$.

This study describes the pharmacokinetics (PK) of BAY 1093884 after single intravenous (IV) and subcutaneous (SC) administration to monkeys. Additionally, the effect on pharmacodynamic (PD) biomarkers after IV and SC administration of BAY 1093884 to normal cynomolgus monkeys and its relation to PK are discussed. The PK/PD model has been developed and could be used to predict the first-inhuman dose for BAY 1093884 that may be used for prophylaxis in patients with hemophilia.

\section{MATERIALS AND METHODS}

\section{Reagents}

BAY 1093884 is a Chinese hamster ovary cell linederived fully human $\operatorname{IgG} 2 \mathrm{mAb}$ directed to human TFPI and cross reactive to monkey, rabbit, dog, rat, and mouse TFPI. Its binding site is located in the K1/K2 domains of TFPI. The drug was supplied as a sterile solution in phosphate-buffered saline (PBS). The concentration of antibody solutions (original or diluted) was confirmed by ultraviolet absorption spectrometry. BAY 1093889 is another antihuman TFPI K2 $\mathrm{mAb}$ and was used to deplete TFPI in monkey plasma. The biotinylated mouse mAb to human TFPI was purchased from R\&D Systems (Minneapolis, MN, USA). Protein characterization and analyses were performed at Bayer (San Francisco, CA, USA). The following tissue/plasma were used: Innovin recombinant human tissue factor (Dade-Behring, Marburg, Germany), FVIII-deficient human plasma (HRF Inc., Raleigh, NC, USA), and pooled cynomolgus monkey plasma (BioreclamationIVT, Westbury, NY, USA). All other chemicals were of reagent grade or better. Animal experiments were conducted in full compliance with local, national, ethical, and regulatory principles and local licensing regulations, per the spirit of the Association for Assessment and Accreditation of Laboratory Animal Care (AAALAC) International's expectations for animal care and use/ethics committees.

\section{Bioanalytical Methods for Measurement of Free and Total Drug Concentrations in Monkey Plasma Samples from PK Studies}

For quantification of BAY 1093884 in plasma samples of monkeys in PK/PD studies, an electrochemiluminescentbased immunoassay (Meso Scale Discovery [MSD], Rockville, MD, USA) platform was employed. Two different MSD formats were used with a lower limit of quantification (LLOQ) of $156 \mu \mathrm{g} / \mathrm{L}$ BAY 1093884. The human IgGcapture generic assay (format 1) was developed for quantification of total BAY 1093884 (free form + bound form) in which only human $\mathrm{IgG}$ is captured by a goat antihuman $\mathrm{IgG}$ antibody preadsorbed by monkey IgGs (SouthernBiotech [catalog number, 2049-01], Birmingham, AL, USA). The
TFPI-capture assay (format 2) was developed for quantification of functional $\mathrm{IgG}$ component (free form of BAY 1093884), which is capable of binding to the antigen TFPI protein.

For analysis of total BAY 1093884 in format 1, Greiner plates were coated with goat antihuman IgG antibody (SouthernBiotech [catalog number, 2049-01]). Bovine serum albumin (BSA) was used as a blocking agent. After incubation with the plasma samples, detection was performed with biotin-conjugated goat antihuman IgG (human fragment antigen-binding [Fab]-specific) antibody (Jackson ImmunoResearch Inc., West Grove, PA, USA) followed by addition of streptavidin-SULFO tag (MSD) for enhanced chemiluminescence (ECL) signals.

For enzyme-linked immunosorbent assay (ELISA) analysis of free BAY 1093884 in format 2, Greiner plates were coated with the recombinant human TFPI protein (R\&D Systems). BSA was used as a blocking agent. After incubation with the plasma samples, detection was performed with biotin-conjugated goat antihuman IgG (fragment crystallizable [Fc]-specific) antibody (Jackson ImmunoResearch Inc.) followed by the addition of streptavidin-SULFO tag (MSD) for ECL signals.

Both assays are qualified and validated. Qualification ranges for LLOQ to the upper limit of quantitation (ULOQ) are 0.156 to $5 \mu \mathrm{g} / \mathrm{mL}$ for TFPI-capture assay and 0.312 to $5 \mu \mathrm{g} / \mathrm{mL}$ for IgG-capture assay. LLOQ and ULOQ are defined as concentrations with accuracy (\% recovery) of $100 \% \pm 25 \%$ variation and precision $(\% \mathrm{CV})$ of $<25 \%$.

Free and total concentrations of BAY 1093884 measured in monkey plasma of the PK/PD study were comparable. Therefore, all other samples were analyzed with the MSD measuring free concentrations (format 2) because this MSD format is applicable to clinical samples.

\section{TFPI-Depleted Cynomolgus Monkey Plasma}

Endogenous TFPI in the plasma of cynomolgus monkeys was depleted using an anti-TFPI antibody coupled to agarose beads. The AminoLink Plus Immobilization Kit (Pierce [catalog number, 44894] Fisher Scientific, Pittsburgh, PA, USA) was used to covalently attach antihuman and monkey TFPI K2 domain antibody BAY 1093889 to a beaded agarose support. The AminoLink Plus Resin contains aldehyde groups that spontaneously and specifically react with primary amines $\left(-\mathrm{NH}_{2}\right)$ present in the target protein. The resulting semistable Schiff base bonds are reduced with sodium cyanoborohydride, resulting in stable secondary amine bonds.

\section{Anti-TFPI Column Preparation}

Coupling of BAY 1093889 to the AminoLink Plus Resin was performed following the manufacturer's instructions. All kit components were used at room temperature (RT), and all AminoLink Plus Column centrifugations were performed at $1000 \times g$ for 1 min using a $15-\mathrm{mL}$ collection tube. The AminoLink Plus Resin was not allowed to become dry at any time.

The pH 7.2 coupling buffer (CB) was prepared by dissolving the contents of $\mathrm{BupH}^{\mathrm{TM}}$ Phosphate Buffered Saline Pack (included in the kit; Fisher Scientific) with $500 \mathrm{~mL}$ of 
deionized filtered water $(0.1 \mathrm{M}$ phosphate, $0.15 \mathrm{M}$ sodium chloride, $\mathrm{pH}$ 7.2). The concentration of BAY 1093889 was $10.89 \mathrm{mg} / \mathrm{mL}$. Three $1-\mathrm{mL}$ vials were pooled and diluted with $9 \mathrm{~mL} \mathrm{CB}(\mathrm{pH} 7.2)$ in a $15-\mathrm{mL}$ conical tube. A small aliquot was saved as the starting, uncoupled control. The AminoLink Plus Resin (2-mL column, 4\% beaded agarose supplied as a $50 \%$ slurry in $0.02 \%$ sodium azide) was suspended by endover-end mixing. To avoid drawing air into the column, the top cap was removed first, followed by the bottom tab. The column was centrifuged to remove the storage buffer, and $2 \mathrm{~mL}$ of $\mathrm{pH} 7.2 \mathrm{CB}$ was added and centrifuged. This was repeated with an additional $2 \mathrm{~mL}$ of $\mathrm{pH} 7.2 \mathrm{CB}$. The bottom cap was replaced, and $5 \mathrm{~mL}$ of BAY 1093889 dissolved in $\mathrm{pH}$ 7.2 CB was added to the AminoLink Plus Column. In a fume hood, $55 \mu \mathrm{L}$ of sodium cyanoborohydride solution (included with kit, $5 \mathrm{M}$ stock solution dissolved in $1 \mathrm{M} \mathrm{NaOH}$ ) was added to the reaction slurry (results in $\sim 50 \mathrm{mM} \mathrm{NaCNBH}_{3}$ ). The top cap was replaced and the column was mixed by rocking end-over-end at RT overnight. Following the overnight incubation of BAY 1093889 with the resin, the top and bottom caps were removed and the column was placed into a new tube and centrifuged to collect nonbound protein. The flow-through was saved and coupling efficiency was determined by comparing the protein concentrations of the nonbound fraction to the starting sample (by measuring the $\mathrm{OD}_{280}$ using a spectrophotometer). This protocol gave a coupling efficiency of $>95 \%$. To block any remaining active sites, the column was washed with $2 \mathrm{~mL}$ of quenching buffer (enclosed with kit, $1 \mathrm{M}$ Tris- $\mathrm{HCl}, 0.05 \%$ sodium azide, $\mathrm{pH}$ 7.4). In a fume hood, $2 \mathrm{~mL}$ of quenching buffer was added to $40 \mu \mathrm{L}$ of sodium cyanoborohydride solution, and the resulting solution was added to the column (results in $50 \mathrm{mM}$ $\mathrm{NaCNBH}_{3}$ ) and mixed gently for $30 \mathrm{~min}$ by end-over-end rocking at RT. Following the quenching step, the column was placed into a new tube and centrifuged to remove quenching buffer. Reactants and noncoupled protein were washed away with $2 \mathrm{~mL}$ of wash solution (included with kit, $1 \mathrm{M} \mathrm{NaCl}$, $0.05 \%$ sodium azide) and centrifuged. This step was repeated four times, and the wash was monitored for the presence of protein.

\section{TFPI Depletion in Monkey Plasma}

Monkey plasma from six males and six females anticoagulated with $3.8 \%$ sodium citrate (lot\# CYN97393, BioreclamationIVT) was pooled for TFPI depletion. The BAY 1093889-coupled column was equilibrated with $30 \mathrm{~mL}$ of phosphate-buffered saline (PBS; 0.1 M phosphate, $0.15 \mathrm{M}$ sodium chloride, $\mathrm{pH}$ 7.2) at $4^{\circ} \mathrm{C}$ using a Pharmacia Biotech PUMP P-50 (Piscataway, NJ, USA) set at a flow rate of $1 \mathrm{~mL} /$ min. The plasma was then loaded onto the column at a starting flow rate of $4 \mathrm{~mL} / \mathrm{min}$. Three initial fractions of $5 \mathrm{~mL}$ each were collected but not included in the TFPI-depleted plasma used for subsequent experimentation. The remaining plasma was loaded onto the column at a flow rate of $0.1 \mathrm{~mL} /$ min. The depleted plasma was reloaded onto the column using the same conditions. All depletion steps were performed at $4{ }^{\circ} \mathrm{C}$. Qualification of TFPI-depleted monkey plasma was assayed by activated partial thromboplastin time (aPTT), prothrombin time (PT), diluted PT (dPT), and TFPI ELISA (Table I). The data indicated that no coagulation
Table I. Qualification of TFPI-Depleted Plasma by aPTT, PT, dPT, and TFPI Levels

\begin{tabular}{lll}
\hline & \multicolumn{2}{l}{ CYN97393 Plasma } \\
\cline { 2 - 3 } & Predepletion & Postdepletion \\
\hline aPTT, s & 47.3 & 48.7 \\
PT, s & 10.5 & 11.9 \\
dPT, s & 259.5 & 171.3 \\
TFPI, ng $/ \mathrm{mL}$ & 29.1 & $<0.7$ \\
\hline
\end{tabular}

aPTT activated partial thromboplastin time, $d P T$ diluted prothrombin time, $P T$ prothrombin time, TFPI tissue factor pathway inhibitor

factors were lost during depletion, only TFPI was removed from the plasma.

\section{FXa Capture ELISA for Measuring Free TFPI in Monkey Plasma}

Ninety-six-well plates (Immunlon ${ }^{\circledR} 2 \mathrm{HB}$; ImmunoChemistry Technologies, Bloomington, MN, USA) were coated with $5 \mu \mathrm{g} /$ well of human FXa in PBS overnight at $4^{\circ} \mathrm{C}$. The plates were blocked with $200 \mu \mathrm{L} /$ well of $1 \%$ BSAPBS for $2 \mathrm{~h}$ at RT. One hundred microliters of 1:10 diluted monkey plasma samples and TFPI calibration plasma (human TFPI spiked in TFPI-depleted monkey plasma range from 0 to $500 \mathrm{ng} / \mathrm{mL}$ ) were added to each well and incubated at RT for $2 \mathrm{~h}$. After wash, $100 \mu \mathrm{L}$ of $0.1-\mu \mathrm{g} / \mathrm{mL}$ biotin-linked antiTFPI polyclonal Ab (R\&D Systems [catalog number, BAF2974]) in 1\% BSA-PBS was added to each well and incubated for $2 \mathrm{~h}$ at RT. After wash, $100 \mu \mathrm{L}$ of 1:200 diluted horseradish peroxidase-conjugated streptavidin (R\&D Systems [catalog number, DY2974E]) was added and incubated for $30 \mathrm{~min}$. The signal was developed by incubation with Amplex red $(33 \mu \mathrm{g} / \mathrm{mL}$, Invitrogen, Eugene, OR, USA) together with $3 \% \mathrm{H}_{2} \mathrm{O}_{2}$ (1/1000 dilution; Sigma-Aldrich, St Louis, MO, USA) in PBS for $30 \mathrm{~min}$ at RT, and read at an excitation wavelength of $485 \mathrm{~nm}$ and an emission wavelength of $590 \mathrm{~nm} . \mathrm{IC}_{50}$ values for BAY 1093884 were derived from the in vitro experiments by spiking serial concentration of BAY 1093884 into pooled normal cyno plasma; TFPI levels were subsequently measured. The $\mathrm{IC}_{50}$ was calculated by nonlinear regression fit (four parameters): log (BAY 1093884 conc) vs. response (free TFPI).

\section{Diluted Prothrombin Time Assay in Cynomolgus Monkey Plasma}

Diluted PT assay in monkey plasma was modified based on a previous report (8). A serial dilution of antibodies starting at $3 \mu \mathrm{M}$ was made in the normal cynomolgus monkey plasma. For each clotting reaction, $50 \mu \mathrm{L}$ of diluted Innovin (recombinant tissue factor, 1/10,000 dilution, $1 \mathrm{pM}$ ) was added to the $50 \mu \mathrm{L}$ of antibody and plasma mixture, and this was followed by incubation at $37^{\circ} \mathrm{C}$ for $4 \mathrm{~min}$. The clotting assay was initiated immediately after addition of $50 \mu \mathrm{L}$ of $\mathrm{CaCl}_{2}$ (HemosIL, Instrumentation Laboratories, Bedford, MA, USA) to a final concentration of $25 \mathrm{mM}$ on the ACL TOP coagulometer (Instrumentation Laboratories). $\mathrm{IC}_{50}$ 
values for BAY 1093884 were derived from the in vitro experiment by spiking serial concentration of BAY 1093884 into pooled normal cyno plasma; dPT clot times were subsequently measured. The $\mathrm{IC}_{50}$ was calculated by nonlinear regression fit (four parameters): $\log$ (BAY 1093884 conc) $v s$. response (dPT clot time).

\section{Dose Administration and Blood Samples}

Cynomolgus monkeys weighing 2 to $4 \mathrm{~kg}$ were used. In the first single-dose IV study, three female cynomolgus monkeys were used for each dose group $(5 \mathrm{mg} / \mathrm{kg}$ over 2- to 5 -min infusions). Blood samples were obtained before and immediately after dose administration and at $5 \mathrm{~min}, 15 \mathrm{~min}$, $30 \mathrm{~min}, 1 \mathrm{~h}, 4 \mathrm{~h}, 8 \mathrm{~h}$, and $24 \mathrm{~h}$ after dosing on day 1 . Additional samples were collected on days $3,7,8,14,16$, and 21.

In the second IV study, the animals were administered single doses of $20 \mathrm{mg} / \mathrm{kg}$ as IV bolus. Two female cynomolgus monkeys were used for each dose group. Blood samples were obtained before and immediately after dose administration and at $15 \mathrm{~min}, 30 \mathrm{~min}, 1 \mathrm{~h}, 4 \mathrm{~h}, 7 \mathrm{~h}, 11 \mathrm{~h}$, and $24 \mathrm{~h}$ after dosing on day 1. Additional samples were collected at $32 \mathrm{~h}$ and on days $2,4,7,10,14,21$, and 28 (days 21 and 28 blood samples in the $20-\mathrm{mg} / \mathrm{kg}$ dose group only).

In another separate SC study, three female cynomolgus monkeys received a 5-mg/kg dose of BAY 1093884 (drug injection volume was $0.5 \mathrm{~mL} / \mathrm{kg}$ body weight). Blood sample collection was performed at the following time points: 0 (predose); 0.5, 1, 2, 4, and $8 \mathrm{~h}$; and days 1, 2, 3, 7, 9, 14, 16, and 22.

All blood samples were collected in $28 \mathrm{G}$ butterfly needle syringes with prefilled anticoagulant $(3.8 \%$ sodium citrate) at a 9:1 ratio (9 volumes of blood to 1 volume of $3.8 \%$ sodium citrate). Plasma was prepared by centrifugation of blood at $10,000 \mathrm{rpm}$ for $10 \mathrm{~min}$ and stored at $-80^{\circ} \mathrm{C}$ until analysis.

\section{Pharmacokinetics and Pharmacodynamics Model}

For noncompartmental PK analysis, PK parameters were calculated from the mean plasma concentrations by noncompartmental analysis using ToxKin software (9). BAY 1093884 displays target-mediated drug disposition (TMDD) in cynomolgus monkeys, as shown from the PK data. Thus, an estimation of PK and therapeutic dose in humans by a conventional species scaling approach was not applicable. Therefore, a mechanistic TMDD model to describe the nonlinear PK of the anti-TFPI antibody was developed. Drug in the central compartment binds to free TFPI according to its binding affinity. Once formed, the antibody-TFPI complex may dissociate or be internalized via receptor-mediated endocytosis and subsequently degraded. Synthesis and degradation rates of TFPI are also accounted for in the model. Additionally, unbound antibody can be directly eliminated from the central compartment or reversibly distributed in other tissues. A quasi-steady-state (QSS) approximation of the full TMDD model was applied, assuming that the drugtarget association and dissociation processes are much faster than the linear processes of drug distribution/elimination (10). The PK analysis for estimating the PK and system parameters was carried out using Phoenix ${ }^{\circledR}$ (version 6.4, Pharsight,
Certara, L.P., Princeton, NJ, USA). Data fitting was performed on the mean values of all measured concentration data applying the naive pooled algorithm. A schematic illustration of the QSS approximation is shown in Fig. 1. The synthesis $\left(K_{\text {syn }}\right)$ and degradation $\left(K_{\mathrm{deg}}\right)$ of free TFPI are also reflected in the diagram (11).

\section{RESULTS}

\section{Pharmacokinetics of BAY 1093884 (IV and SC) in Cynomolgus Monkeys}

The PK and disposition profile of BAY 1093884 was evaluated in conscious female cynomolgus monkeys (weight range, 2-4 kg) obtained from Hartelust BV (Tilburg, The Netherlands). BAY 1093884 was administered as a single intravenous 2-min infusion at $5 \mathrm{mg} / \mathrm{kg}$ or single intravenous bolus doses $(<30 \mathrm{~s})$ of $20 \mathrm{mg} / \mathrm{kg}$ after cannulation of a superficial limb vein. For the SC administration, a single injection was administered in the lateral chest wall.

Monkey PK samples were analyzed by using both IgGcapture and TFPI-capture assay formats (Fig. 2a, b). BAY 1093884 showed a similar PK profile using the two assay formats. Time versus concentration profiles are shown in Fig. 2c, d. Nonlinear drug concentration versus time profiles were observed after 5- and 20-mg/kg IV doses in cynomolgus monkeys (Fig. 2e). In Table II, the PK parameters were calculated based on data generated from the IgG-capture assay only. The half-life, clearance (CL), and volume of distribution at steady state after the $5-\mathrm{mg} / \mathrm{kg}$ IV dose were $28 \mathrm{~h}, 1.2 \mathrm{~mL} / \mathrm{h} / \mathrm{kg}$, and $48 \mathrm{~mL} / \mathrm{kg}$, respectively. The half-life, clearance, and volume of distribution at steady state after the $20-\mathrm{mg} / \mathrm{kg}$ IV dose were $67 \mathrm{~h}, 0.6 \mathrm{~mL} / \mathrm{h} / \mathrm{kg}$, and $71 \mathrm{~mL} / \mathrm{kg}$, respectively. The time to maximum concentration $\left(t_{\max }\right)$ and maximum plasma concentration $\left(C_{\max }\right)$ after the $5-\mathrm{mg} / \mathrm{kg} \mathrm{SC}$ dose were $48 \mathrm{~h}$ and $23 \mu \mathrm{g} / \mathrm{mL}$, respectively. SC bioavailability is estimated to be $52 \%$ (range $48-56 \%, n=3$ ). Table II shows PK parameters generated from the TFPI-capture assay. The half-life, clearance, and volume of distribution at steady state

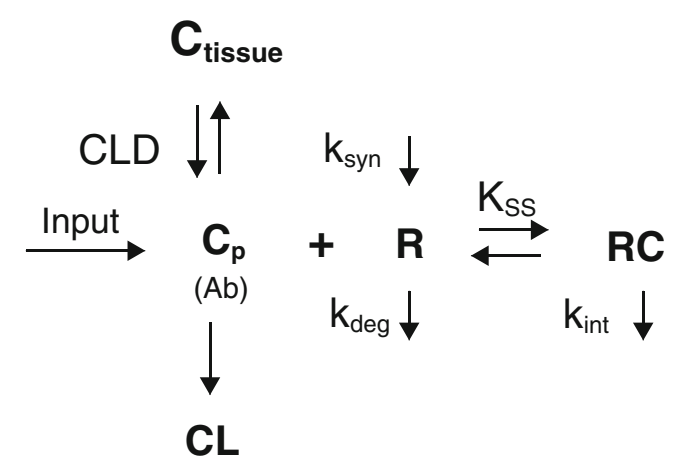

Fig. 1. TMDD model describing nonlinear PK of BAY 1093884. Drug in the central compartment $\left(C_{p}\right)$ can distribute to tissue sites $\left(C_{\text {tissue }}\right.$, $C L D)$, be eliminated from the system $(C L)$, or bind to the TFPI target $(R)$ to form a drug-target complex $(R C)$. This complex then either dissociates or rebinds $\left(K_{s s}\right)$ or is internalized and degraded $\left(K_{\text {int }}\right) . C L$ plasma clearance, $C L D$ distribution plasma clearance (plasma to tissue), $k_{\text {deg }}$ receptor degradation rate, $k_{\text {int }}$ internalization rate of RC, $K_{s s}$ steadystate rate constant, $k_{s y n}$ receptor synthesis rate, $P K$ pharmacokinetics, $R$ receptor, $R C$ tissue factor pathway inhibitor-drug complex, TMDD target-mediated drug deposition 
a
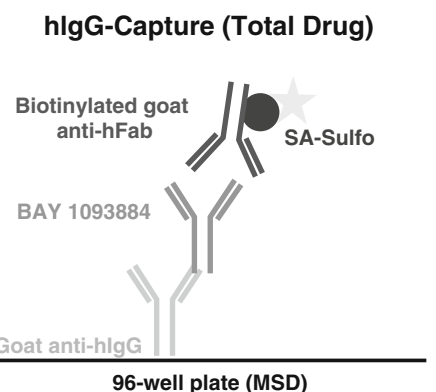

b

TFPI-Capture (Free Drug)

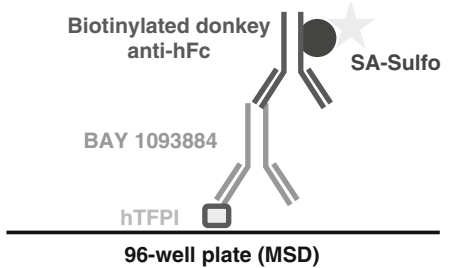

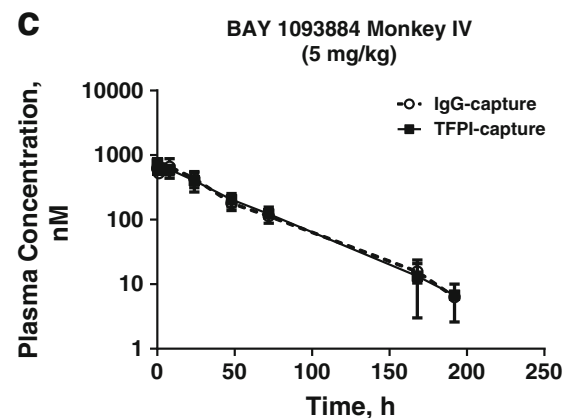
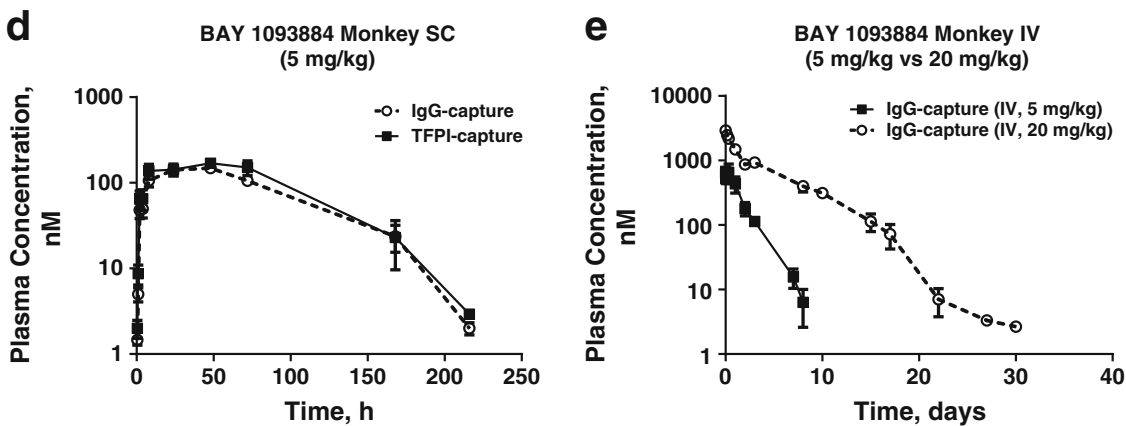

Fig. 2. Bioanalytical methods for measurement of plasma a total drug and $\mathbf{b}$ free drug concentrations in monkey plasma samples. The concentration versus time profiles of BAY 1093884 at $5 \mathrm{mg} / \mathrm{kg}(n=3)$ in the cynomolgus monkey after $\mathbf{c}$ IV and d SC administration (mean $\pm \mathrm{SD}$ ); e plasma concentration versus time profiles of BAY 1093884 in the cynomolgus monkey after IV administration of $5 \mathrm{mg} / \mathrm{kg}$ (solid squares) and $20 \mathrm{mg} / \mathrm{kg}$ (solid circles). hFab human fragment antigen-binding; $h F c$ human fragment crystallizable, $h I g G$ human IgG, $h T F P I$ human TFPI, $I g G$ immunoglobulin G, $I V$ intravenous, $S C$ subcutaneous, $M S D$ meso scale discovery, TFPI tissue factor pathway inhibitor

are nearly identical by both assay formats. SC bioavailability is estimated to be $61 \%$ (range $57-74 \%, n=3$ ) using the TFPIcapture assay format.

\section{Pharmacodynamics of BAY 1093884 in Cynomolgus Monkeys}

\section{Free TFPI Assay}

To measure functional free TFPI in cynomolgus plasma after administration of BAY 1093884, we have developed a quantitative ELISA assay using TFPI-depleted cynomolgus plasma. Free TFPI in plasma, which does not bind BAY 1093884, will bind to the FXa on plates. Free TFPI levels in normal monkey plasma ranged from 18 to $52 \mathrm{ng} / \mathrm{mL}$
(Table III). Similar free TFPI levels in normal and hemophilic plasma were observed. A half-maximal inhibitory concentration $\left(\mathrm{IC}_{50}\right)$ value of $4.65 \mathrm{nM}$ was observed for reduction in free TFPI in cynomolgus plasma by BAY 1093884 (Fig. 3a).

After IV dosing of BAY 1093884 at $5 \mathrm{mg} / \mathrm{kg}$, TFPI levels in two of three cynomolgus monkeys were maintained at low levels for 7 to 8 days; in one animal, the TFPI levels were back to normal at day 7 after dosing (Fig. 4a). After a single IV administration of $20 \mathrm{mg} / \mathrm{kg}$ BAY 1093884, free TFPI levels were suppressed to $<10 \%$ of the baseline level for 17 days in all three animals (Fig. 4b).

After SC dosing of BAY 1093884 at $5 \mathrm{mg} / \mathrm{kg}$, plasma TFPI levels in all three cynomolgus monkeys dropped to $\sim 50 \%$ of baseline in $30 \mathrm{~min}$ and to $<10 \%$ at $1 \mathrm{~h}$; TFPI levels remained low until day 3 , started to rise at day 7 , and returned to predose levels at days 9 to 22 (Fig. 4c).

Table II. Pharmacokinetic Parameters of BAY 1093884 in Cynomolgus Monkeys by IgG-Capture and TFPI-Capture Assays

\begin{tabular}{|c|c|c|c|c|c|c|c|c|c|}
\hline Assay and route & Dose, $\mathrm{mg} / \mathrm{kg}$ & $\mathrm{AUC}_{\text {norm }}, \mathrm{kg} \mathrm{h} / \mathrm{L}$ & $t_{1 / 2}, \mathrm{~h}$ & MRT, h & $C_{\max }, \mu \mathrm{g} / \mathrm{mL}$ & $t_{\max }, \mathrm{h}$ & $\mathrm{CL}, \mathrm{mL} / \mathrm{h} / \mathrm{kg}$ & $V_{\mathrm{ss}}, \mathrm{mL} / \mathrm{kg}$ & Mean $\% F$ \\
\hline \multicolumn{10}{|c|}{ IgG capture (total drug) } \\
\hline IV & 5 & 845 & 28 & 40 & $\mathrm{nc}$ & $\mathrm{nc}$ & 1.2 & 48 & $\mathrm{nc}$ \\
\hline IV & 20 & 1667 & 67 & 118 & $\mathrm{nc}$ & $\mathrm{nc}$ & 0.6 & 71 & $\mathrm{nc}$ \\
\hline $\mathrm{SC}$ & 5 & 440 & 26 & 69 & 23 & 48 & $\mathrm{nc}$ & $\mathrm{nc}$ & 52 \\
\hline \multicolumn{10}{|c|}{ TFPI capture (free drug) } \\
\hline IV & 5 & 832 & 25 & 40 & $\mathrm{nc}$ & $\mathrm{nc}$ & 1.2 & 48 & $\mathrm{nc}$ \\
\hline $\mathrm{SC}$ & 5 & 517 & 26 & 68 & 25 & 48 & $\mathrm{nc}$ & $\mathrm{nc}$ & 61 \\
\hline
\end{tabular}

$\% F$ bioavailability, $A U C_{n o r m}$ dose-normalized area under the curve, $C_{\max }$ maximum observed concentration, $C L$ clearance, $I g G$ immunoglobulin G, $I V$ intravenous, $M R T$ mean residence time, $n c$ not calculated, $S C$ subcutaneous, $t_{1 / 2}$ half-life, $t_{\max }$ time of maximum observed concentration, TFPI tissue factor pathway inhibitor, $V_{s s}$ volume of distribution at steady state 
Table III. Free TFPI Levels in Plasma from Normal Cynomolgus Monkeys

\begin{tabular}{llc}
\hline Plasma lot number from cynomolgus monkeys & Sex & Mean \pm SD TFPI, ng/mL \\
\hline CYN97393 & $\mathrm{F}$ & $25.59 \pm 4.24$ \\
CYN82245 & $\mathrm{F}$ & $31.60 \pm 5.98$ \\
CYN93315 & $\mathrm{M}$ & $24.90 \pm 6.71$ \\
CYN91464 & $\mathrm{M}$ & $43.14 \pm 8.88$ \\
CYN91465 & $\mathrm{F}$ & $28.76 \pm 4.95$ \\
TFPI-depleted cynomolgus plasma & $\mathrm{n} / \mathrm{a}$ & $<$ LLOQ \\
\hline
\end{tabular}

$L L O Q$ lower limit of quantitation, $n / a$ not applicable, TFPI tissue factor pathway inhibitor

\section{Diluted Prothrombin Time Assay}

We have employed a second functional clotting assay to evaluate the PD of BAY 1093884. dPT assay is an extrinsic pathway-based assay with coagulation activated by the action of thromboplastin (tissue factor) on FVII/FVIIa. If functional TFPI is present in the plasma, the FVIIa will be inhibited, and FXa generation will be blocked; in turn, the dPT clotting time will be prolonged. In the presence of anti-TFPI-neutralized $\mathrm{Ab}$, TFPI will be inhibited, thereby restoring the TF-initiated coagulation. In this assay, an $\mathrm{IC}_{50}$ value of $6.19 \mathrm{nM}$ was observed for shortening dPT clotting time in cynomolgus plasma by BAY 1093884 (Fig. 3b). After IV dosing of BAY 1093884 at $5 \mathrm{mg} / \mathrm{kg}$, similar to TFPI levels, dPT clotting time was shortened for 7 to 8 days in two of three cynomolgus monkeys; in only one animal did the dPT clotting return to baseline levels at day 7 (Fig. 5a).

After SC dosing of BAY 1093884 at $5 \mathrm{mg} / \mathrm{kg}$, dPT clotting shortened in all three monkeys immediately after dosing $(<1 \mathrm{~h})$ and was maintained at a shortened clot time (146-190 s) until day 7, and then started to rise at day 9, returning to predose levels (>240 s) at days 9 to 22 (Fig. 5b).

\section{PK/PD Correlation of BAY 1093884 in Cynomolgus Monkeys}

Drug concentration, plasma TFPI levels, and dPT time course are shown in Fig. 6. After the $5-\mathrm{mg} / \mathrm{kg}$ dose of anti-
TFPI mAb IV and/or SC, TFPI levels decreased to a minimum of $<10 \%$ at the earliest sampling time $(5 \mathrm{~min}$ ) for IV and at $1 \mathrm{~h}$ for SC and maintained at the lowest within $72 \mathrm{~h}$, then gradually returned to baseline. Around days 7 to 8 , TFPI levels remained at $50 \%$ inhibition; the drug concentration at this time was approximately $1.62 \mu \mathrm{g} / \mathrm{mL}(10.1 \mathrm{nM})$.

Generally, dPT decreased from a predose value of 260 to $280 \mathrm{~s}$ to $\sim 160 \mathrm{~s}$ at the earliest time after drug administration for IV or SC. Similarly to TFPI, around days 7 to 8 , dPT clotting increased by 50 to $60 \mathrm{~s}$ and remained at $\sim 50 \%$ inhibition; the drug concentration at this time point was approximately $1.65 \mu \mathrm{g} / \mathrm{mL}(10.3 \mathrm{nM})$.

The above data showed that both free TFPI and dPT profiles are inversely correlated to drug concentration after administration of IV and SC BAY 1093884, clearly demonstrating the PK/PD relationship in cynomolgus monkeys.

\section{PK/PD Modeling}

The concentration versus time $(c / t)$ profiles of BAY 1093884 and free TFPI in plasma after IV administration of 5 and $20 \mathrm{mg} / \mathrm{kg}$ to cynomolgus monkeys were fitted simultaneously using a mechanistic TMDD model as described in the "Materials and Methods." A good agreement between observed and fitted concentrations was obtained, and all parameters including TFPI synthesis and degradation rate could be estimated (Fig. 7).

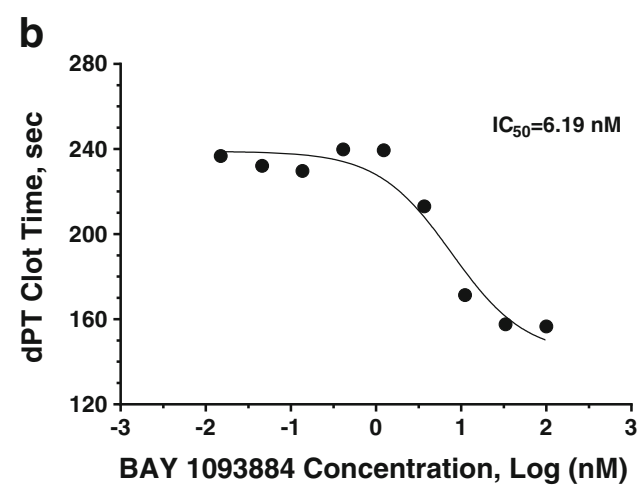

Fig. 3. $\mathrm{IC}_{50}$ of BAY 1093884 in cynomolgus plasma. BAY 1093884 was spiked in normal cynomolgus monkey plasma, and a free TFPI in plasma was measured against the calibration curve by FXa-captured ELISA. \% inhibition of TFPI = (concentration of TFPI with BAY 1093884 - background $) /($ concentration of TFPI without BAY 1093884 - background). b dPT clotting time was measured in ACL TOP coagulometer. $d P T$ diluted prothrombin time, ELISA enzyme-linked immunosorbent assay, $F X a$ activated factor $\mathrm{X}, I C_{50}$ half-maximal inhibitory concentration, $T F P I$ tissue factor pathway inhibitor 
a

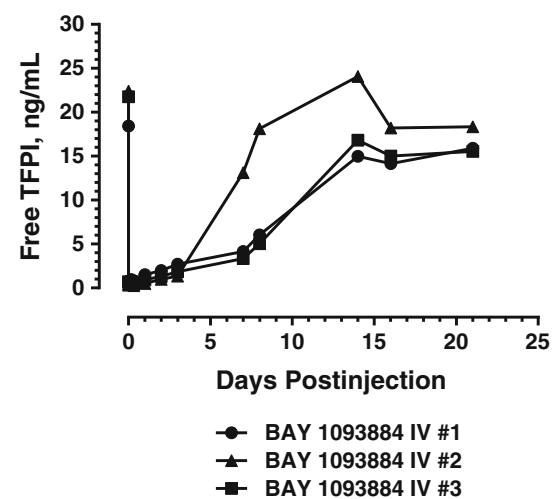

b

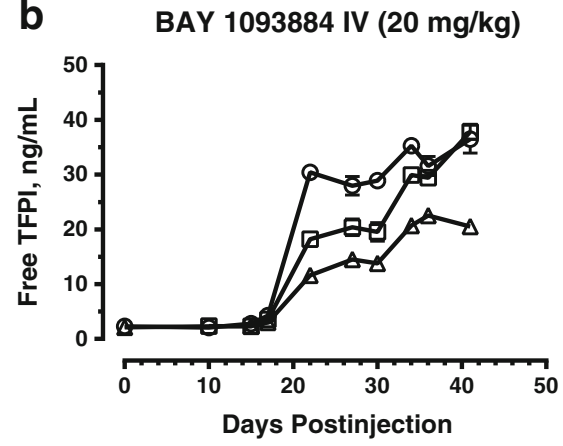

も BAY 1093884 IV \#7 ○ BAY 1093884 IV \#8 $\star$ BAY 1093884 IV \#9
C BAY $1093884 \mathrm{SC}(5 \mathrm{mg} / \mathrm{kg})$

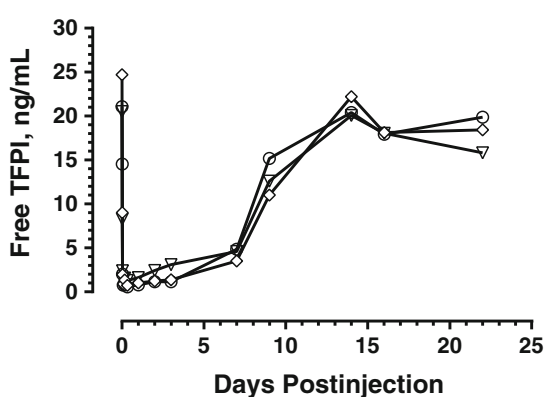

๑ BAY 1093884 SC \#4 $\rightarrow$ BAY 1093884 SC \#5 $\curvearrowright$ BAY 1093884 SC \#6

Fig. 4. Plasma free TFPI levels versus time profiles following single-dose administration of BAY 1093884 to cynomolgus monkeys. a IV administration at $5 \mathrm{mg} / \mathrm{kg}$, b IV administration at $20 \mathrm{mg} / \mathrm{kg}$, c SC administration at $5 \mathrm{mg} / \mathrm{kg}$. $I V$ intravenous, $S C$ subcutaneous, TFPI tissue factor pathway inhibitor

We simulated target occupancy (\%) after IV infusion of different doses in humans using the model developed. At $0.4 \mathrm{mg} / \mathrm{kg}$, TFPI inhibition is expected to be between 83 and $93 \%$ up to $24 \mathrm{~h}$. $\left.\mathrm{AUC}_{(0-168} \mathrm{h}\right)$ is estimated to be about $147 \mathrm{mg}^{*} h / L$, and $C_{\max }$ is expected to be about $7.8 \mathrm{mg} / \mathrm{L}$. This is close to the other anti-TFPI antibody reported in the phase 1 trial $(0.25 \mathrm{mg} / \mathrm{kg}$, IV) (12).

\section{DISCUSSION}

Monoclonal antibodies have unique PK properties that are not solely defined by the structure of the mAbs. The concentration and distribution of the target antigen can have a significant impact on the PK of mAbs as well as on PK linearity (13-16). It is important to consider the bioanalytical (immuno)assay specificity (for example, whether one is measuring the concentration of bound, free, or total mAbs) when comparing the PK behavior of different mAbs.

In this study, TFPI mAb (BAY 1093884) immunoassay measured free drug (TFPI mAb) and total drug (TFPI Ab and TFPI Ab-TFPI complex) concentration in blood. BAY 1093884 at a dose of $5 \mathrm{mg} / \mathrm{kg}$ IV and SC showed similar PK profiles for free drug and total drug using the two assay formats; this similarity is likely the result of the administration of a saturating dose of TFPI mAb and a very low concentration of TFPI in plasma $(1.6 \mathrm{nM})$. The PK profiles of both assays show similar elimination phase half-life $(25-28 \mathrm{~h})$ in cynomolgus monkeys administered $5 \mathrm{mg} / \mathrm{kg}$ BAY 1093884.

The PK of therapeutic mAbs is determined by target/ receptor- and nontarget-mediated mechanisms influencing the (non)linearity of this process. TMDD is one of the key determinants of the PK of therapeutic mAbs and has been widely described, especially for mAbs binding to cell surface targets and high endogenous target levels. Clearance via the target-mediated pathway is influenced by interaction of the $\mathrm{mAb}$ with the neonatal $\mathrm{Fc}$ receptor $(\mathrm{FcRn})$, which recycles the mAb back into the extracellular fluid (17). However, this target-mediated clearance mechanism is saturable and can lead to a nonlinearity in PK. The PK at different doses can provide useful information about saturation because the halflife will increase with increasing dose as the FcRn receptor is progressively blocked.

According to Deng et al. (18), the CL of $12 \mathrm{mAbs}$ in cynomolgus monkeys with linear PK ranged from $\sim 5$ to $12 \mathrm{~mL} / \mathrm{day} / \mathrm{kg}$. Other investigators reported CL values for mAbs with linear and nonlinear PK ranging from 4 to
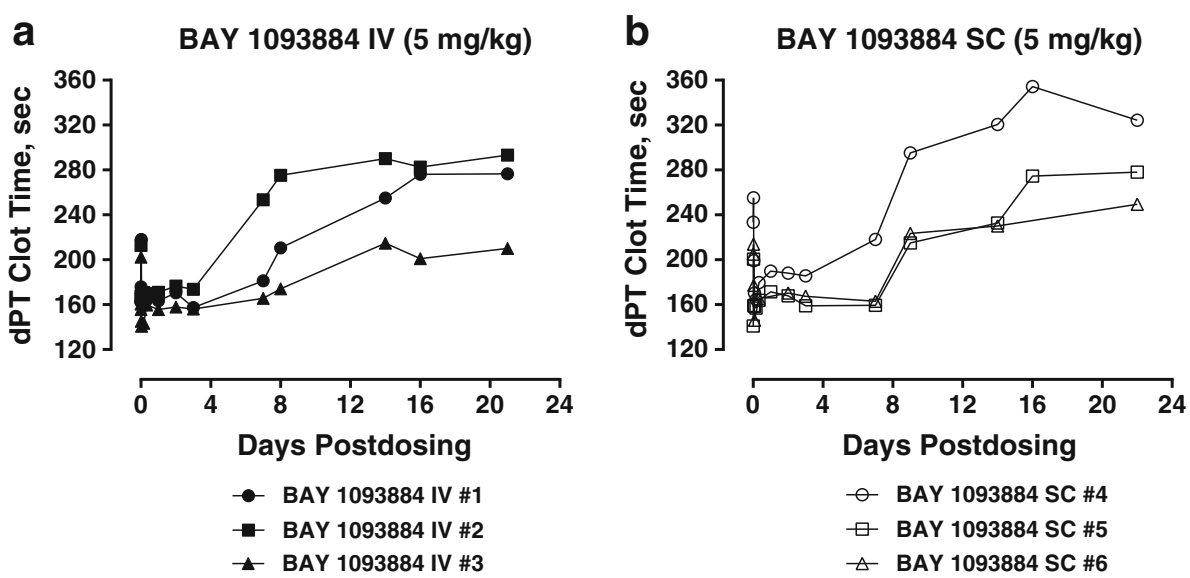

Fig. 5. Plasma dPT clotting time versus time profiles following single-dose administration of BAY 1093884 to cynomolgus monkeys. a IV administration at $5 \mathrm{mg} / \mathrm{kg}$, b SC administration at $5 \mathrm{mg} / \mathrm{kg}$. $d P T$ diluted prothrombin time, $I V$ intravenous, $S C$ subcutaneous 
a

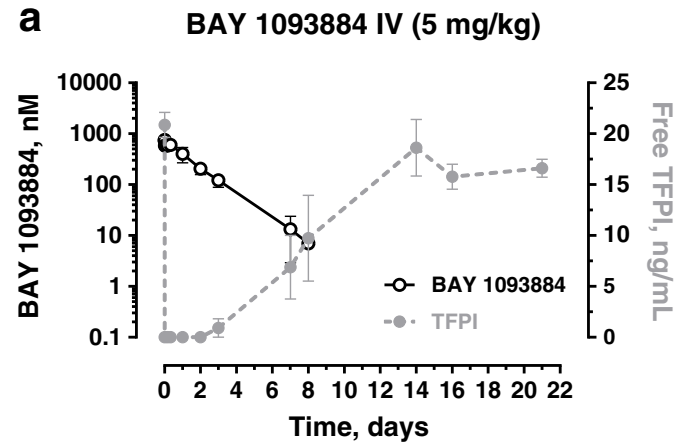

C
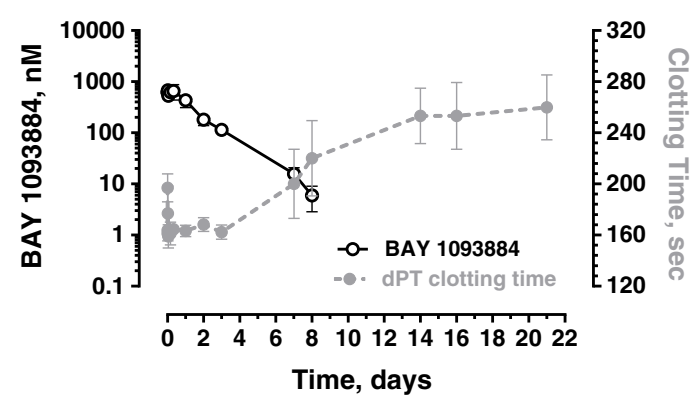

b

BAY $1093884 \mathrm{SC}(5 \mathrm{mg} / \mathrm{kg})$

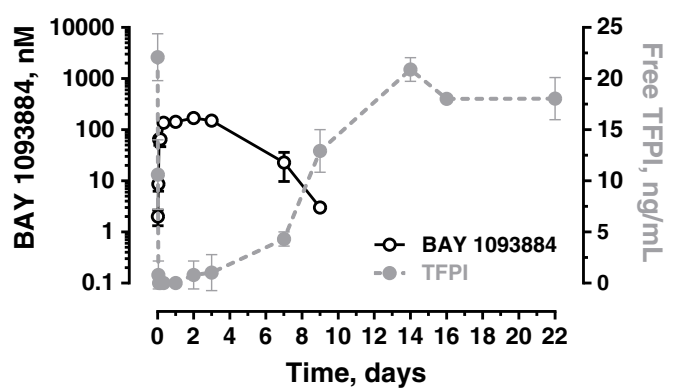

d BAY $1093884 \mathrm{SC}(5 \mathrm{mg} / \mathrm{kg})$

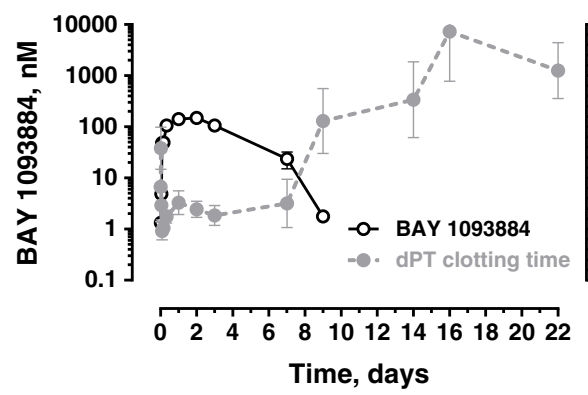

Fig. 6. PK/PD correlation of BAY 1093884 in cynomolgus monkeys. a Observed BAY 1093884 concentrations and free TFPI versus time profiles following single IV administrations of $5 \mathrm{mg} / \mathrm{kg}$ BAY 1093884. b Observed BAY 1093884 concentrations and free TFPI versus time profiles following single SC administration of $5 \mathrm{mg} / \mathrm{kg}$ BAY 1093884. c Observed BAY 1093884 concentrations and dPT clotting time versus time profiles following single IV administration of $5 \mathrm{mg} / \mathrm{kg}$ BAY 1093884. d Observed BAY 1093884 concentrations and dPT clotting time versus time profiles following single SC administration of $5 \mathrm{mg} / \mathrm{kg}$ BAY 1093884. $d P T$ diluted prothrombin time, $I V$ intravenous, $S C$ subcutaneous, TFPI tissue factor pathway inhibitor

$206 \mathrm{~mL} / \mathrm{day} / \mathrm{kg}$ in nonhuman primates (19). In our study, antiTFPI Ab had a CL of $28.8 \mathrm{~mL} / \mathrm{day} / \mathrm{kg}$ at the $5-\mathrm{mg} / \mathrm{kg}$ dose in cynomolgus monkeys. CL at the $20-\mathrm{mg} / \mathrm{kg}$ dose was $14.4 \mathrm{~mL} /$ day $/ \mathrm{kg}$, indicating nonlinear PK. Additionally, the half-life of BAY 1093884 was significantly shorter than seen for other therapeutic antibodies in cynomolgus monkeys, further indicating a TMDD mechanism for BAY 1093884. This is consistent with another anti-TFPI antibody $(12,20)$.

There are two forms of TFPI, TFPI $\alpha$ and TFPI $\beta$. In vivo, most TFPI ( $\sim 85 \%$; mainly TFPI $\beta$ ) is expressed on the surface of vascular endothelial cells. Approximately $10 \%$ of TFPI $(\mathrm{TFPI} \alpha)$ circulates in plasma at a concentration of approximately $1.6 \mathrm{nM}$ in humans (2). Approximately 5\% of TFPI is present within resting platelets. The endothelium surface TFPI antigen might have an impact on the disposition of this humanized TFPI mAb, but further investigation is warranted.

As with the one-target TMDD model, the drug-target association process is usually much faster than the processes of drug dissociation/distribution/elimination and of elimination of the target and the drug-target complex (11).

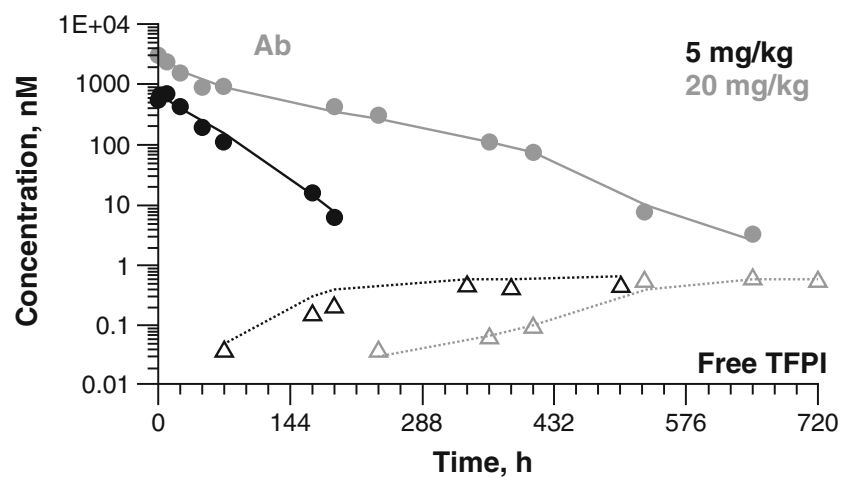

\begin{tabular}{lccc}
\hline Parameter & Unit & Estimate & CV, \% \\
\hline $\mathrm{CL}$ & $\mathrm{L} / \mathrm{h}^{*} \mathrm{~kg}$ & 0.000287 & 16.7 \\
$\mathrm{CLD}$ & $\mathrm{L} / \mathrm{h}^{*} \mathrm{~kg}$ & 0.000645 & 11.1 \\
$\mathrm{Vc}$ & $\mathrm{L} / \mathrm{kg}$ & 0.0491 & 4.13 \\
$\mathrm{Vt}$ & $\mathrm{L} / \mathrm{kg}$ & 0.0606 & 6.8 \\
$\mathrm{k}_{\text {syn }}$ & $\mathrm{nM}^{*} \mathrm{~h}^{-1}$ & 2.60 & 12.4 \\
$\mathrm{k}_{\text {deg }}$ & $\mathrm{h}^{-1}$ & 4.11 & 25.1 \\
$\mathrm{k}_{\text {int }}$ & $\mathrm{h}^{-1}$ & 55.4 & 16.1 \\
$\mathrm{~K}_{\text {sS }}$ & $\mathrm{nM}$ & 232 & 7.53 \\
\hline
\end{tabular}

Fig. 7. Observed and fitted concentrations of BAY 1093884 and TFPI after IV administration of 5, and $20 \mathrm{mg} / \mathrm{kg}$ (two experiments) to cynomolgus monkeys. Symbols observed concentrations, lines fitted concentrations; dotted line free TFPI concentrations, solid line antibody drug concentrations. Ab antibody, $C L$ clearance, $C L D$ intercompartmental clearance, $C V$ coefficient of variation, $I V$ intravenous, $k_{\text {deg }}$ target degradation rate constant, $k_{\text {int }}$ internalization rate constant, $K_{s s}$ steadystate rate constant, $k_{\text {syn }}$ target synthesis rate constant, TFPI tissue factor pathway inhibitor, $V c$ volume of the central compartment, $V t$ tissue volume 
Additionally, in this example, the rate of elimination of the complex is not negligible compared with the dissociation rate. Therefore, a QSS approximation was applied as follows: the steady-state constant $\left(K_{\mathrm{ss}}=\mathrm{KD}+k_{\text {int }} / k_{\mathrm{on}}\right)$ was introduced, and the number of unknown parameters was reduced $\left(k_{\text {off }}\right.$ disappears from the equation). Upon fitting of the concentration versus time profiles of BAY 1093884 and free TFPI to the QSS model, a good correlation between observed and fitted concentrations was obtained (Fig. 7). Furthermore, this model could be easily applied to human dose prediction in the assumption that (1) unbound fractions of free TFPI are similar in female and male cynomolgus monkeys and humans and (2) human PK and system parameters (synthesis and degradation rates of TFPI $\left[k_{\mathrm{syn}}, k_{\mathrm{deg}}\right]$, internalization rate of the complex $\left.\left[k_{\text {int }}\right]\right)$ can be obtained by single-species scaling from monkeys.

During drug research and development, it is usually preferred to measure free drug and free target concentrations if feasible because the free concentrations directly drive efficacy and reflect target coverage. To describe the mechanistic properties of TFPI $\mathrm{mAb}$, the PK/PD model was developed to describe the change of free TFPI and its complex concentration in blood. dPT has been considered as a clinically relevant measurement of blood clotting and is used for detection of any abnormality of the extrinsic pathway in the coagulation system (21). We have employed dPT assay as a second PD assay to evaluate how well free TFPI functions as a predictive PD marker. As shown in Fig. 6, both free TFPI and dPT profiles correlate with drug concentration similarly after IV and SC administration to cynomolgus monkeys.

The variation of free TFPI in the IV dose group (Fig. 4a) is much greater than that in the SC dose group (Fig. 4c). This is likely associated with the variability of drug clearance in different animals because the initial drug load and base TFPI levels are similar in all animals dosed at $5 \mathrm{mg} / \mathrm{kg}$ (IV and SC).

There are several major catabolisms for TFPI Ab drug in vivo. Immediately after administration of TFPI $\mathrm{mAb}$, nearly all of the circulating free TFPI was bound to TFPI $\mathrm{mAb}$. After this initial increase in TFPI Ab-TFPI complex, the formation rate of complex is determined by the production rate of free TFPI in blood. Meanwhile, the free $\mathrm{mAb}$ in blood will also bind to TFPI $\beta$ on the endothelium, where the complex might be internalized and degraded. Lastly, the free $\mathrm{mAb}$ and mAb-TFPI complex also binds to FcRn on the endothelium. The FcRn-bound Ab-TFPI complex is internalized into endocytic vesicles, where the TFPI are degraded, while free $\mathrm{Ab}$ recycles back into the blood circulation.

\section{CONCLUSION}

In conclusion, both $\mathrm{dPT}$ and free TFPI preclinical PD markers correlated well with concentration of the $\mathrm{Ab}$ after single-dose administration of BAY 1093884 to cynomolgus monkeys. A mechanistic TMDD model and several modifications of it have been established and applied to describe the nonlinear PK of BAY 1093884, and this model was able to describe the dose-dependent effect of TFPI mAb on the suppression of TFPI activity and the prolongation of dPT response in cynomolgus monkeys. The $k_{\mathrm{on}}$ and $\mathrm{KD}$ values as determined by in vivo modeling and via Biacore in vitro are very similar. The highest parameter precision was achieved in the model assuming irreversible binding to the target without internalization. The system parameters as determined in monkeys using a TMDD-based model can easily be scaled to humans, and an efficacious dose can be estimated. The present model was developed on the concept of antibodyligand interaction and should be generally applicable to the study of response profiles of therapeutic mAbs in the clinical setting.

\section{ACKNOWLEDGEMENTS}

We would like to thank Jens Schroeder and Joachim Fruebis for critical review of the manuscript. This study was funded by Bayer Pharma AG (Leverkusen, Germany). All authors reviewed and approved the final draft of the manuscript. Editorial assistance was provided by Complete Healthcare Communications, LLC (Chadds Ford, PA, USA) and was fully funded by Bayer.

\section{COMPLIANCE WITH ETHICAL STANDARDS}

Conflict of Interest J.-M. Gu, E. Ho, K. Tran, and T. Myles were employees of Bayer at the time this study was conducted. X.-Y. Zhao, B. Subramanyan, and C. Patel are employees of Bayer. T. Schwarz, J. Schuhmacher, A. Baumann, and M. Koellnberger are employees of Bayer AG.

Open Access This article is distributed under the terms of the Creative Commons Attribution 4.0 International License (http://creativecommons.org/licenses/by/4.0/), which permits unrestricted use, distribution, and reproduction in any medium, provided you give appropriate credit to the original author(s) and the source, provide a link to the Creative Commons license, and indicate if changes were made.

\section{REFERENCES}

1. Broze Jr GJ, Girard TJ. Tissue factor pathway inhibitor: structure-function. Front Biosci (Landmark Ed). 2012;17:26280 .

2. Dahm A, Van Hylckama Vlieg A, Bendz B, Rosendaal F, Bertina RM, Sandset PM. Low levels of tissue factor pathway inhibitor (TFPI) increase the risk of venous thrombosis. Blood. 2003;101:4387-92.

3. Girard TJ, Warren LA, Novotny WF, Likert KM, Brown SG, Miletich JP, et al. Functional significance of the Kunitz-type inhibitory domains of lipoprotein-associated coagulation inhibitor. Nature. 1989;338:518-20.

4. Wood JP, Bunce MW, Maroney SA, Tracy PB, Camire RM, Mast AE. Tissue factor pathway inhibitor-alpha inhibits prothrombinase during the initiation of blood coagulation. Proc Natl Acad Sci U S A. 2013;110:17838-43.

5. Erhardtsen E, Ezban M, Madsen MT, Diness V, Glazer S, Hedner $\mathrm{U}$, et al. Blocking of tissue factor pathway inhibitor (TFPI) shortens the bleeding time in rabbits with antibody induced haemophilia A. Blood Coagul Fibrinolysis. 1995;6:388-94.

6. Liu T, Scallan CD, Broze Jr GJ, Patarroyo-White S, Pierce GF, Johnson KW. Improved coagulation in bleeding disorders by non-anticoagulant sulfated polysaccharides (NASP). Thromb Haemost. 2006;95:68-76. 
7. Waters EK, Genga RM, Schwartz MC, Nelson JA, Schaub RG, Olson KA, et al. Aptamer ARC19499 mediates a procoagulant hemostatic effect by inhibiting tissue factor pathway inhibitor. Blood. 2011;117:5514-22.

8. Jin Y, Yegneswaran S, Gu JM, Gritzan U, Schonfeld DL, Paz P, et al. Identification and function probing of an antithrombin IIIbeta conformation-specific antibody. J Thromb Haemost. 2016;14:356-65.

9. Entimo AG. ToxKin user manual. Berlin, Germany; 2010.

10. Gibiansky L, Gibiansky E, Kakkar T, Ma P. Approximations of the target-mediated drug disposition model and identifiability of model parameters. J Pharmacokinet Pharmacodyn. 2008;35:573-91.

11. Mager DE, Jusko WJ. General pharmacokinetic model for drugs exhibiting target-mediated drug disposition. J Pharmacokinet Pharmacodyn. 2001;28:507-32.

12. Chowdary P, Lethagen S, Friedrich U, Brand B, Hay C, Abdul Karim F, et al. Safety and pharmacokinetics of anti-TFPI antibody (concizumab) in healthy volunteers and patients with hemophilia: a randomized first human dose trial. J Thromb Haemost. 2015;13:743-54.

13. Davis CB, Bugelski PJ. Subcutaneous bioavailability of a PRIMATIZED IgG1 anti-human CD4 monoclonal antibody is dose dependent in transgenic mice bearing human CD4. Drug Deliv. 1998;5:95-100.

14. Davis CB, Garver EM, Kwok DC, Urbanski JJ. Disposition of metabolically radiolabeled CE9.1 - a macaque-human chimeric anti-human CD4 monoclonal antibody-in transgenic mice bearing human CD4. Drug Metab Dispos. 1996;24:1032-7.
15. Mould DR, Davis CB, Minthorn EA, Kwok DC, Elliott MJ, Luggen ME, et al. A population pharmacokinetic-pharmacodynamic analysis of single doses of clenoliximab in patients with rheumatoid arthritis. Clin Pharmacol Ther. 1999;66:246-57.

16. Mould DR, Baumann A, Kuhlmann J, Keating MJ, Weitman S, Hillmen $P$, et al. Population pharmacokineticspharmacodynamics of alemtuzumab (Campath) in patients with chronic lymphocytic leukaemia and its link to treatment response. Br J Clin Pharmacol. 2007;64:278-91.

17. Roopenian DC, Akilesh S. FcRn: the neonatal Fc receptor comes of age. Nat Rev Immunol. 2007;7:715-25.

18. Deng R, Iyer S, Theil FP, Mortensen DL, Fielder PJ, Prabhu S. Projecting human pharmacokinetics of therapeutic antibodies from nonclinical data: what have we learned? MAbs. 2011;3:616.

19. Tseng CM, Faggioni R, Roskos LR. Pharmacokinetics of human therapeutics characterized in nonhuman primates. In: Bluemel J, Korte S, Schenck GF, Weinbauer G, editors. The nonhuman primate in nonclinical drug development and safety assessment. Cambridge: Elsevier; 2015. p. 359-75.

20. Agerso H, Overgaard RV, Petersen MB, Hansen L, Hermit MB, Sorensen $\mathrm{MH}$, et al. Pharmacokinetics of an anti-TFPI monoclonal antibody (concizumab) blocking the TFPI interaction with the active site of FXa in Cynomolgus monkeys after iv and sc administration. Eur J Pharm Sci. 2014;56:65-9.

21. Dahm A, Rosendaal FR, Andersen TO, Sandset PM. Tissue factor pathway inhibitor anticoagulant activity: risk for venous thrombosis and effect of hormonal state. Br J Haematol. 2006;132:333-8. 